\title{
A DEMOCRATIZAÇÃO DO ENSINO E O TRATAMENTO DAS DESIGUALDADES SOCIAIS NO ENSINO/APRENDIZAGEM INTERCULTURAL DE LÍNGUAS ESTRANGEIRAS.
}

\section{La Démocratisation de L’Enseignement et Le Traitement des Inégalités Sociales dans L' Enseignement / Apprentissage Interculturel de Langues Étrangères}

\section{Resumo}

O ensino/aprendizagem de línguas estrangeiras tem sido, ao longo dos anos, caracterizado por um certo elitismo, porquanto, por várias razões, eram as minorias oriundas de estratos sociais mais privilegiados que a ele acediam. A democratização do ensino e a sua conseqüente massificação em todos os níveis de escolaridade na Europa do séc. XX tomou esta aprendizagem, em princípio, acessível a todos. Tomando como exemplo o caso de Portugal, em que esta democratização ocorreu a partir de 1974, com a instituição de um regime democrático, defendemos a tese de que o fato de se viver num regime democrático não é por si só bastante para acabar com desigualdades sociais. São necessárias medidas políticas diferenciadas que facultem aos mais carentes os meios que lhes permitam aceder ao conhecimento, o que, por sua vez, lhes facilitará uma plena integração. As políticas protecionistas que as jovens democracias têm a tendência de implementarpodem serperversas na medida em que, não ajudando o cidadão a desenvolver a sua maionidade, perpetuam as desigualdades que se pretendiam eliminar. Consideramos fundamental o acesso de todos à aprendizagem das línguas estrangeiras, cujo domínio se toma cada vez mais importante na época da globalização. Para tal, preconizamos um ensino diferenciado em paralelo com uma escola pública devidamente equipada com todos os recursos técnicos e humanos necessários e adequados, de modo a proporcionar esse acesso aos que dele mais necessitam.

Palavras-chave: Democratização do ensino; aprendizagem de línguas estrangeiras.

Professora da Faculdade de Ciências Sociais e Humanas da Universidade Nova de Lisboa, Departamento de Línguas, Culturas e Literaturas Modernas-Estudos Alemães (área de especialização: Didática/Formação de Professores). Correio Eletrônico: acc@fcsh.unl.pt 


\section{Résumé}

Le processus - enseignement / apprentissage de langues étrangères vient caracterisé, au fil des années, par un certain élitisme, ainsi, pour plusieurs motifs la minorité de personnes venues des extraits socials plus privilegiées y accedaient. La démocratisation de l' enseignement et sa conséquente "massification" en tous les niveaux d'escolarité en Europe du XXème siècle a determiné cette apprentissage au début, accessible à tous.

En profitant de l'exemple du cas de Portugal où cette démocratisation s'est passée a partir de 1974 basée sur l'institution du Régime Démocratique, on défend la tese que la façon de vivre dans un régime démocratique n'est pas suffisant pour finir les inégalités sociales. Des mésures politiques diferenciées sontimportantes pourpermettre l'accès à la connaissance aux plus défavorisés ce que pourra faciliter une pleine intégration.

Les politiques protectionnistes que les jeunes democraties ont la tendence d'exécuter peuvent être perverses à mesure que ne permettent pas le développement des citoyens et perpetuentles inégalités qu'on veutéliminier. On considère fondamental l'accès de tous à l'apprentissage de langues étrangeres dont la connaissance devient chaque fois plus importante dans cette époque de mondialisation. C'estpourcela qu'on privilegie l'enseignement différencié à côté d'une école laïque bien équipée de ressources techniques et humaines necessaires et adaptés pour permettre cet accès aux plus défavorisés.

Mots-clefs: Démocratisation de l' enseignement; Apprentissage de langues étrangères.

\section{Introdução}

Até à segunda metade do século $\mathrm{XX}$, a aprendizagem escolar de línguas estrangeiras tinha, na Europa Ocidental, um carácter elitista, constituindo um privilégio das minorias mais cultas por serem estas as que tinham acesso à educação não elementar. Privilégio, primeiro porque as línguas estrangeiras predominantes, o inglês e o francês, só se aprendiam a partir do quinto ano de escolariade e, segundo, por duas diferentes razões de exclusão: nos países mais industrializados, como por exemplo a Alemanha, ainda que a escolaridade obrigatória fosse de 9 anos, estas duas línguas só se aprendiam no único tipo ${ }^{2}$ de escola que dava acesso à Universidade, Gymnasium, frequentado nos finais dos anos 50 por apenas $10 \%$ da população escolar (NEUNER, 1997, p. 15). Por outro lado, nos países periféricos do Sul, como Portu-

As outras escolas são: Realschule com a duração de 5 ou 6 anos e Hauptschule 4 ou 5 anos, dependendo do Land e, a partir dos anos 80, em alguns Länder, a Gesamtschule que congrega todos os tipos de escola, exceto os últimos anos do Gymnasium. Este tem a duração de 9 anos. 
A democratização do enino e o tratamento das desigualdades sociais no ensino/aprendizagem ...

gual, ainda que estas línguas se aprendessem nos três tipos ${ }^{3}$ de escolas existentes à época, a maior parte da população juvenil estava à partida excluída desta aprendizagem, visto a escolaridade obrigatória se resumir a apenas quatro anos.

Enquanto na Alemanha Federal esta situação se começou a alterar nos anos $60 \mathrm{com}$ as reformas no sistema educativo que, entre outros, introduziram o ensino da língua inglesa para todos, ou seja, passando esta disciplina a ser ministrada nos três tipos de escola, a ela tinham acesso todos os alunos da escolaridade obrigatória; paralelamente, e resultante também de modificações socioeconômicas, tornou-se mais premente a necessidade de ser proficiente em línguas estrangeiras, pelo que as Ciências de Educação começaram a debruçar-se sobre o estudo de alternativas às tradicionais formas de educação, tendo também a área específica das línguas sofrido fortes alterações, desenvolvendo novas abordagens às matérias que as constituiam.

Em Portugal, a política educativa só mudou radicalmente a partir de 25 de abril de 1974, com o restabelecimento da democracia - a Lei Fundamental consagra o direito de todos ao ensino, garantindo o direito à igualdade de oportunidades de acesso e êxito escolar (nos.1 e 2 do Art. 0 74). Em 1986, com a adesão de Portugal à União Européia, sentiu-se a necessidade de uma reestruturação curricular, estando agora em curso outra reforma, na sequência de uma avaliação dos resultados do ensino após trinta anos de democracia e numa tentativa de melhor integrar os objetivos das políticas educativas que vêm sendo delineadas pela União Européia e pelo Conselho da Europa.

Como consequência da democratização do ensino em Portugal, foram extintos os três tipos de escolas do ensino não obrigatório, por serem consideradas discriminatórias e classistas, passando a existir uma única, cuja estrutura é em tudo semelhante ao antigo liceu. Ao longo dos anos, têm-se verificado alguns ajustamentos dado o vazio, fundamentalmente em formação técnica elementar, que se tem vindo a sentir ao longo das três décadas de democracia na sociedade portuguesa. Ou seja: ao tentar acabar-se com as descriminações sociais, criando-se um único tipo de escola, e não se tendo compensado a anterior aquisição de saberes diversificados com políticas educativas adequadas, formou-se uma sociedade na qual estão ausentes conhecimentos elementares das áreas comerciais, técnicas e indústriais, que marcam o atual estado do país.

O liceu com 7 anos, a escola industrial e a escola comercial com 5 anos. Esta estrutura foi alterada com a Revolução de 1974 que acabou com estas escolas, dando lugar a uma única, estruturada em Ensino Preparatório, 5.ํ e 6.ํaํ. Ensino Básico - do 5.ํa ao 9.ํano - e Secundário - primeiro do 10. ao 11.ำ e depois (1980-81) até ao 12.‥ Atualmente, só existe a denominação de Ensino Básico - até ao 9.ํano, incluindo os 4 anos do antigo primário - e Secundário do 10.ํa 12.․․ 
Uma outra transformação decorrente da democratização tem a ver com o alargamento da escolaridade obrigatória primeiro para 6 anos e depois para 9 anos, do que resultou a massificação do ensino. O atual governo, o XV, na reforma curricular que iniciou, e com a qual está a tentar colmatar os males atrás mencionados, instituiu os 12 anos de escolaridade obrigatória para os jovens que a partir de 2005/6 comecem a freqüentar o quinto ano. Uma das críticas a esta medida é precisamente a de que primeiro se deveria investir na presença dos jovens na atual escola de nove anos (v. Mapa 3) e, só depois de atingido este objetivo, deveria-se então alargar o número de anos do ensino obrigatório. No fundo, muito do que se tem feito nestes últimos vinte anos tem mais a ver com 'operações de cosmética' para 'União Européia ver', do que com políticas educativas eficientes que contribuam para desenvolver solidamente a sociedade.

\section{a) Razões históricas recentes (1926 a 1974):}

As medidas de política educativa levadas a cabo pelo regime fascista de 1926 que, entre outros, reduziu a escolaridade obrigatória de seis para quatro anos e depois para três, que mandou fechar as escolas normais onde se formavam os professores para o ensino primário e todas as escolas primárias que não tivessem um mínimo de 45 alunos - medidas que afectaram fundamentalmente as regiões rurais, conforme Melo (1978, p. 26), ainda hoje são visíveis na estrutura social do país. Apesar desta situação ter sofrido algum recuo nos anos 50, com a escolaridade obrigatória fixada nos 4 anos e dando-se início a uma massiva alfabetização de adultos, visto 'os 40 por cento de analfabetos proclamados pelas estatísticas revelarem um país demasiado "subdesenvolvido" para ser bem aceite no mercado mundial' (ibid. p. 27), tal não impede que se chegue a 1974 com uma parte da população portuguesa analfabeta e uma grande parte de analfabetos funcionais. Segundo estatísticas de 1970, de uma população residente com 10 anos e mais, totalizando 7.031.125, 25,5\% eram analfabetos, (MELO, 1978, p. 24). As taxas de analfabetismo mais elevadas localizavam-se numa faixa do interior raiano sul centro, regiões rurais em que predominava a grande propriedade agrícola - Beja, Évora Portalegre e Castelo Branco - e as menos elevadas nos grandes centros urbanos, Lisboa e Porto, regiões onde se verificava uma estrutura industrial nascente, muito concentrada. Num estudo sobre a literacia em Portugal apresentado em 1996 por Ana Benavente et al., constata-se que 'a percentagem de pessoas sem qualquer grau de ensino completo é ainda muito elevada no país $(17,8 \%)^{\prime}$ e 'que a maior parte $(14,4 \%)$ nunca frequentou sequer o sistema de ensino' (ibid. p. 
30), acrescentando que, segundo o Censo de 1991, os analfabetos literais representam ainda hoje $11,0 \%$ da população com 10 ou mais anos (ibid. p. 395).

As medidas do regime totalitário que procuraram manter o povo português num nível escolar extremamente baixo, com uma maior incidência nas populações rurais do interior a Norte e a Sul, por oposição ao litoral e aos dois centros urbanos aqui localizados, marcam fortementemente a situação que ainda hoje se vive em Portugal, caracterizada pelo abandono do campo e sua conseqüente desertificação com a deslocação das populações para os centros urbanos e para o litoral. Esta situação está patente na mancha que reflete o atual índice de desenvolvimento econômico e social (v. Mapa 1) e o índice de educação (v. Mapa 2$)^{4}$ que regista também naquelas zonas um alto índice de abandono escolar (v. Mapa 3) e/ ou saída antecipada. Em 2001, a taxa de saída precoce ${ }^{5}$ situava-se nos 44\%, segundo dados do Ministério da Educação.

Nesta época, como já foi referido no início, e à semelhança do que acontece hoje em dia para a $1 .^{\mathrm{a}}$ e $2 .{ }^{\mathrm{a}}$ língua estrangeira, a aprendizagem iniciava-se respectivamente no quinto ano de escolaridade, durante cinco anos, e no sétimo durante três anos. A 3. $\stackrel{\text { a }}{\text { o }}$ Alemão, iniciava-se no décimo ano, durante dois anos exclusivamente para os futuros germanistas e juristas.

\section{Atual contextualização}

Na fase da adesão à União Européia, Portugal está teoricamente ao nível dos seus parceiros da União, pois ao alargar a escolaridade a nove anos, permite o acesso de muito mais cidadãos àquilo que sempre existiu no sistema, mas que até à data era privilégio de uns poucos, ou seja, no que concerne à aprendizagem da língua estrangeira, cinco anos para consolidar os conhecimentos de uma $1 .{ }^{\mathrm{a}}$, e três de iniciação a uma $2 .{ }^{\mathrm{a}} 6$.

4 Mapas in: http://www.min-edu.pt, 28.10.2003.

5 Entende-se por abandono: os indivíduos com 10-15 anos que não concluíram o 3ํㅜciclo (ensino obrigatório) e não se encontram a freqüentar a escola; saída antecipada: indivíduos com 1824 anos que não concluíram o $3^{\circ}$ ciclo e não se encontram a freqüentar a escola; saída precoce: indivíduos com 18-24 que não concluiram o ensino secundário e não se encontram a freqüentar a escola.

6 As línguas estrangeiras atualmente disponíveis são: inglês, francês, alemão e espanhol. A sua escolha por parte dos alunos é livre, estando no entanto sujeita a um número mínimo de alunos (25, ou 15 se é opção) para se constituir uma turma e à oferta da própria escola, ou seja, as escolas não são obrigadas a disponibilizar estas quatro línguas, podendo condicionar ou

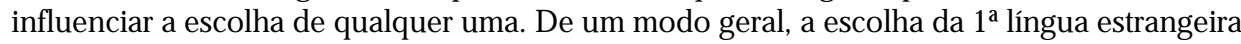
recai no inglês. 
Mas, observando as altas taxas de analfabetismo e de analfabetismo funcional ou iliteracia ${ }^{7}$ no nosso país, facilmente se conclui que o fosso existente entre nós e os países mais desenvolvidos da UE é grande. A constatação pelos diversos governos, dos baixos níveis de escolaridade da população e a necessidade de apresentar 'boas estatísticas' à União, levaram a que se instalassem políticas proteccionistas e de facilitismo que, a nosso ver, mais não fizeram do que fomentar o grau de iliteracia, alargando ainda mais a distância que já nos separava dos outros países comunitários e reforçando entre nós as características de um não-desenvolvimento.

É neste contexto de políticas proteccionistas e de facilitismo, certamente bem intencionadas que, na nossa opinião, as desigualdades se acentuam, promovendo ainda mais a exclusão, o que nos parece comprovado dados os fracos resultados obtidos a nível geral de desenvolvimento do país, como as estatísticas 0 atestam.

Temos como fundamental que, no ensino, as desigualdades e a exclusão se combatem globalmente com a exigência e a simultânea disponibilização de meios. Tal requer não só mais investimento na educação tanto de materiais como de recursos humanos mas, e sobretudo, uma muito boa gestão destes recursos. E é fundamentalmente quanto a este aspecto que residem os maiores constrangimentos. $\mathrm{O}$ pouco que se vai tendo acontece graças às verbas com que a UE participa, estando ainda por equipar e funcionar em grande parte das escolas, a par da formação específica do pessoal docente. Para as LE é significativo 0 alheamento, não se encontrando estas mencionadas uma única vez tanto "nos compromissos para o setor" como nas "políticas de orientação geral"s , apesar da União Européia ter como prioridade nas políticas educativas que todos os cidadãos da Europa sejam competentes efetivos em pelo menos três línguas. Parece-nos no entanto evidente que esta competência adquire-se melhor em escolas devidamente equipadas e com pessoal docente devidamente formado.

\section{A União Européia e as línguas estrangeiras}

A aprendizagem de duas línguas estrangeiras no ensino obrigatório é, como vimos, bastante recente. No ensino secundário, todos os cursos dão continuidade a uma das línguas durante dois ou três anos, podendo somente

7 O conceito de alfabetização traduz o ato de ensinar e de aprender (a leitura, a escrita e 0 cálculo) enquanto literacia traduz a capacidade de usar as competências (ensinadas e aprendidas) de leitura de escrita e de cálculo (Ana Benavente et al.:4).

8 in: http://www.min-edu.pt 
os alunos de línguas e literaturas modernas optar por iniciar uma terceira língua pelo mesmo período de tempo.

Com a adesão de Portugal à União Européia em 1986, as suas políticas educativas passaram a ter de se pautar também pelas recomendações elaboradas pelo conjunto dos seus Membros, que seguem não só as correntes mais modernas em termos didático-pedagógicos, mas têm em linha de conta a mobilidade acadêmica e profissional dos seus cidadãos, bem como a crescente globalização. Numa Europa com origens étnicas, culturais e linguísticas diversas, será mais importante do que nunca que os seus cidadões possuam as competências necessárias para entender os seus vizinhos e com eles comunicar. Aprender e falar outras línguas incentiva uma maior abertura aos outros, às suas culturas e maneiras de vêr o mundo, contribuindo para reforçar no cidadão o espírito de abertura e de tolerância culturais.

Os indivíduos que possuam boas competências linguísticas podem tirar maior partido da liberdade de trabalhar ou estudar noutro Estado Membro. O desenvolvimento do espírito empresarial e das competências dos cidadãos será mais facilmente levado a cabo se a aprendizagem de línguas for promovida com eficácia, zelando para que os cidadãos e as empresas da Europa possuam as competências linguísticas e interculturais indispensáveis a uma presença forte no mercado global ${ }^{9}$. Considera ainda a União Européia que o leque de línguas faladas pelos europeus é reduzido, limitando-se fundamentalmente ao inglês, francês, alemão e espanhol, reconhecendo também que as competências linguísticas se distribuem de forma desigual por países e grupos sociais.

É neste contexto que a UE preconiza para os seus cidadãos o domínio efetivo de três línguas da União, incentivando desde 1997 o seu ensino precoce e uma oferta diversificada.

\section{Modelo didático}

Para que estes objetivos se possam atingir, é também importante sensibilizar os pais, preparar os professores para as novas necessidades bem como desenvolver e divulgar materiais didáticos incluindo os recursos multimídia.

$\mathrm{O}$ atual modelo de ensino/aprendizagem de línguas estrangeiras implica mais do que uma aprendizagem meramente técnica (regras, gramática e vocabulário); considera também as vertentes comportamentais, sociais e cul-

9 in: Promover a aprendizagem das línguas e a diversidade linguística: Um Plano de Ação 20042006, http://www.europa.eu.int/, 28.10.2003. 
turais, definindo-se em perspectivas e critérios que ultrapassam o quadro da tradicional educação 'nacional'. Este modelo insere-se num contexto pragmático-funcional que, de um modo geral na Europa Ocidental data de meados dos anos 70 do século XX, modelo que nos anos 80 foi enriquecido com 0 conceito intercultural, o que lhe confere o caráter cultural interativo.

A competência intercultural assume um lugar de destaque no processo de aquisição da $L E$ porquanto é por meio desta que se processa a comunicação com o outro. Para que essa comunicação se estabeleça e desenvolva é necessário, no entanto, dispor basicamente não só dos elementos do código linguístico (gramática, vocabulário, regras de construção de palavras, sintaxe, fonética, ortografia), mas também das competências discursiva, estratégica e sociocultural, do que resulta a competência comunicativa. Definindo-se de um modo mais preciso a competência sociocultural, esta integra as áreas: savoir être, savoir apprendre, savoir, savoir faire, consistindo esta última na capacidade do falante em integrar as três anteriores em situações reais de contato bicultural, o que é crucial na transição da teoria comunicativa para a intercultural (CCC, p. 40).

Considerando que a competência sociocultural é uma parte integrante da aquisição da língua estrangeira, a partir da qual se estimula a apetência para melhor conhecer o outro, produzindo-se estados de empatia e uma interação com a sua cultura, estão criadas as condições que levam ao desenvolvimento da competência intercultural, o que, por sua vez, conduzirá a um melhor conhecimento da sua própria cultura e a uma auto-reflexão e predisposição para eventuais mudanças de atitude em relação a si próprio e em relação ao outro (AFONSO, p. 17). Para o autor H.J. Krumm (1994, p. 27), a dimensão intercultural alarga-se ainda à pesquisa das causas da desigualdade, de teor étnico, político, econômico e de políticas linguísticas.

No ensino em Portugal, são estes também os princípios orientadores que regem a aquisição das línguas estrangeiras, conforme consta das organizações curriculares e programas. Mas, no nosso sistema escolar, as línguas estrangeiras não são alvo de sucesso, verificando-se até um desinteresse geral na sua aprendizagem e domínio, não existindo no entanto dados sobre as efetivas competências linguísticas dos cidadãos. Haverá inúmeras razões que justifiquem este desinteresse, desde a massificação do ensino com turmas demasiado grandes, até as muitas carências de índole social e do próprio sistema educativo, passando pela pesada herança de um sistema político isolacionista do passado e pela posição geográfica do país, no extremo ocidental da Europa. Não podemos nos esquecer também do fraco poder econômico da população em geral, o que não facilita as deslocações ao estrangeiro com estadias mais ou menos prolongadas. 
O grande salto que veio contrariar esta tendência foi dado em 1986 com a adesão de Portugal à União Européia. Os apoios financeiros disponibilizados em geral têm fomentado o desenvolvimento econômico, proporcionando mais riqueza, o que permite à população uma maior mobilidade $\mathrm{e}$ abertura para com o exterior. Por outro lado, os apoios financeiros atribuídos à educação em geral e à aprendizagem e consolidação da língua estrangeira em particular financiam projetos de intercâmbios escolares, estágios e visitas de estudo no exterior para formação de professores de línguas estrangeiras (LÍNGUA) - e estadias de um ou mais semestre para estudantes universitários (ERASMUS), subprogramas no quadro SOCRATES. Esta mobilidade tem facultado uma melhor percepção e um maior conhecimento do exterior, aliado a um melhor conhecimento linguístico e sociocultural dos países em questão, deixando nesses mesmos países um melhor conhecimento da nossa cultura.

São igualmente atribuídas verbas para promoção do eLearning nos estabelecimentos de ensino (MINERVA) que incentivam a utilização de computadores, de instrumentos multimídia e da Internet, bem como a provisão da formação de docentes sobre como utilizar e ensinar a utilizar as tecnologias modernas. Existe igualmente uma série de outros programas, que no entanto não estão diretamente ligados à aquisição de línguas estrangeiras, ainda que 0 estejam indiretamente na medida em que criam redes de intercâmbio de informações e criação de materiais didáticos europeus.

\section{Da teoria à prática}

Se é certo que muito tem sido feito neste campo, a verdade é que há ainda muitíssimo por fazer, nomeadamente equipar as escolas com o material necessário e em número suficiente de modo que permita uma utilização razoável por parte de cada aluno, desde o computador e Internet até aos materiais de multimídia e passando pela formação de professores contemplando estes aspectos.

Num país como Portugal, geograficamente distante e com todos os constrangimentos socioeconômicos e de literacia já mencionados, a Internet desempenha um papel relevante na tomada de consciência intercultural na aquisição das línguas estrangeiras bem como no tratamento dos correlacionados conhecimentos socioculturais. São numerosos os links com materiais de ensino desde os exercícios de gramática até aos de conteúdo sociocultural. Pode ainda recorrer-se a artigos de jornais aqui publicados, a informações de todo o tipo sobre o/os assunto/s que se pretendam investigar e ainda a imagens de cidades, paisagens, museus, exposições, etc., etc.,, permitindo visitas virtuais a espaços fechados e abertos dos países que de outro modo seria 
dificil, senão impossível, para muitos visitar. A disponibilização destes materiais em escolas de todos os níveis permite também que todos os alunos, independentemente do seu status social ou outro, 'viagem' visitando países, neles ir a restaurantes, ver ementas e tipos de comida, visitar aeroportos e estações de transportes públicos, aprender a ver horários, visitar centros culturais, ver hotéis e como fazer reservas, e todo um sem número de situações que constituem o dia-a-dia dos cidadãos de determinado país, passando pela sua história e até localização geográfica. Sem dúvida que o tratamento de todos estes aspectos terá de ser orientado pelo professor, que com a devida formação será capaz de orientar os seus alunos na procura e recolhimento de materiais, ao mesmo tempo em que cria neles autonomia de trabalho, de modo a que estes possam desenvolver as suas competências fora da supervisão do professor. A Internet e o computador não devem ser considerados o único instrumento de trabalho, mas sim como mais um meio de apoio a ser utilizado como complementaridade de outros.

Aqui desenvolve-se em primeiro lugar a compreensão escrita, podendo no entanto desenvolver-se também a produção escrita por e-mails e a oral por chats. Tanto a produção escrita como a oral podem ainda ser desenvolvidas ou exercitadas por pequenos relatórios ou exposições orais. Uma vantagem acrescida é a de tanto os principiantes como os mais avançados nos conhecimentos linguísticos se poderem servir deste meio sem que as diferenças de conhecimentos se evidenciem ou se tornem um obstáculo e este funcionar inclusivamente como motivação para avançar na aprendizagem, despertando o interesse pelo conhecimento do outro. Em questão de motivação há que referir igualmente que a utilização de e-mails e chats confere à língua um enquadramento autêntico.

Uma das disciplinas curriculares do ensino não superior que a tutela atual está a valorizar muito, ainda que esteja a ser implementada de um modo irregular, é precisamente da área de informática: Tecnologias de Informação e Comunicação. Cabe recordar, no entanto, que ainda há bem pouco tempo, alunos do $10^{\circ}$ ano de uma escola dos arredores de Lisboa não dispunham de computadores para a disciplina, aprendendo somente a teoria. Este exemplo pode certamente extrapolar-se para 0 resto do país, pois grande parte das escolas de todos os níveis de ensino não está ainda devidamente equipada com computadores e menos ainda com ligação à Internet.

As próprias Universidades, nos seus departamentos de línguas, não possuem nem mediotecas nem modernos, ou sequer antigos, laboratórios de línguas, não estando as salas de aula equipadas com material audiovisual. Em termos de instalações com computadores e ligação à Internet, tem-se verificado uma crescente aquisição deste material, sendo no entanto ainda muito insuficiente face às necessidades. Com as fortes 
A democratização do enino e o tratamento das desigualdades sociais no ensino/aprendizagem ...

restrições orçamentais em curso, não se prevê que a situação melhore em qualquer nível de ensino, o que de novo constrangirá a formação dos mais carentes.

Segundo um artigo publicado do jornal diário 'Público' em 4 de julho de 2003, mais de metade dos estudantes portugueses do ensino não universitário possuem e usam em casa computador. Segundo este mesmo artigo, reportando-se a um estudo elaborado pelo Ministério da Educação, os rapazes gostam mesmo é de jogar, ainda que também naveguem na Internet e escrevam textos. As jovens, pelo contrário, preferem escrever textos e entrar em chats. Ainda segundo este estudo, os estudantes usam o computador em casa mais para jogar do que para fazer trabalhos escolares, sendo que $47 \%$ nunca 0 utilizaram para esses trabalhos. São ainda os alunos que vivem nas regiões mais urbanas que passam mais horas por semana em frente ao monitor. $\mathrm{O}$ estudo demonstra ainda que é à medida que a escolaridade aumenta que os pais vão considerando a disciplina em questão mais importante, já que são os alunos mais velhos que têm computador próprio. Quanto ao uso das novas tecnologias na escola, no ano de 2005, 36\% dos alunos afirmam que não 0 fizeram. O computador continua sendo, portanto, pouco aproveitado nos estabelecimentos de ensino. Interessante e indo ao encontro da idéia que defendemos quanto ao aproveitamento do computador e Internet no tratamento das desigualdades sociais, verificou-se neste inquérito que é nas zonas mais desfavorecidas que mais se usa o computador, significando isto também na opinião da coordenadora do estudo Jacinta Paiva, que a utilização deste meio pode contribuir para nivelar as condições sociais e culturais do país.

\section{Conclusões}

Uma característica dos países em desenvolvimento não é tanto a falta de meios, mas sim a incapacidade de gerir adequadamente esses meios. Esta característica expande-se, no entanto, a todos os países que, devido à conjuntura econômica internacional e interna, vêem-se obrigados a fortes restrições orçamentais cujas primeiras vítimas são geralmente a saúde e a educação. Cria-se assim um círculo vicioso, pois não se pode melhorar a formação por falta de verbas e não se cria riqueza por falta de formação. A grande questão está em como romper este círculo: em Portugal verificaram-se significativas melhorias com um regime democrático que, no entanto, teve que ser reforçado com a sua integração num grande grupo econômico que compreende que sem educação não há desenvolvimento e que o desenvolvimento só é completo quando integra o aspecto humano e o material. 


\section{Referências}

AFONSO, Clarisse da Conceição Alves e Costa. Competência Intercultural conteúdos culturais na aquisição da língua estrangeira e sua integração didáctica no ensino do Alemão. 2002. Tese (Doutorado) - Lisboa, 2002.

- Wer hat Angst vor Landeskunde, Disponível em: <http:// www.fcsh.unl.pt/deps/ estudos alemães/CCAfonsoWerHatAngst.htm>. Acesso em: 2001.

BENVENTE, Ana; et al. A literacia em Portugal. Lisboa: Fundação Calouste Gulbenkian/Conselho Nacional de Educação, 1996.

COMMUNAUTÉS EUROPÉENNES, Gouvernance européenne - Livre Blanc. Office des publications officielles des Communautés européennes. Luxembourg: [S.n.], 2001.

COUNCIL FOR CULTURAL CO-OPERATION. Modern Languages: Learning, Teaching, Assessment. A Common European Framework of reference, Strasbourg: European Council, 1998.

KRUMM, Hans-Jürgen. Mehrsprachigkeitund interkulturelles Lemen. O rientienung im Fach Deutsch als Fremdsprache. Jahrbuch Deutsch als Fremdsprache, $n$. 20, p. 13-36, 1994.

MELO, Alberto; BENVENTE, Ana. Educação popular em Portugal (19741976), Lisboa: Livros Horizonte, 1978.

EUROPEAN COMMISSION, European Union-supported educational research 1995-2003 - Briefing papers for policy makers, Report Editor: Angelos S. Agalianos, Directorate-General for Research, EUR 20791, 2003.

NEUNER, Gerhard; HUNFELD, Hans, Methoden des fremdsprachlichen Deutschunterrichts. Berlin: Langenscheidt, 1997.

Endereços na Internet:

http://www.min-edu.pt/

http://www.deb.min-edu.pt/

http://www.des.min.edu-pt/

http://www.europa.eu.int/

Recebido: 10 de outubro de 2005.

Aceito: 19 de dezembro de 2005. 